\title{
UN ENCUENTRO CON LOS MAYAS
}

\author{
Ana Luisa IzQuierdo \\ Centro de Estudios Mayas, UNAM
}

\begin{abstract}
A través del vínculo entre un hombre y los restos de una cultura, aquél, después de largos años de fructífera labor, logró lo que anhe. laba: restituirle al pueblo maya de hoy parte de su pasado; poderle dar una ubicación más precisa en tiempo y espacio, sacar a la luz parte de los restos materiales de sus ancestros, mostrarle cómo dominaban la naturaleza, cómo se organizaron, cuáles fueron sus inquietudes, cómo las resolvieron, en fin, enseñarle una parcela de su gran. dioso pasado. Ese hombre fue Alberto Ruz.
\end{abstract}

Después de una adolescencia rica en experiencia, transcurrida entre la escuela de su natal Francia y la Universidad de La Habana, de donde era originario su padre, llegó a México en 1935. Desde ese entonces comenzó a empaparse de nuestro ser, a recorrer el territorio mexicano y a enterarse de nuestras antigüedades.

Por boca de la Doctora Adelaida de Juan, quien a las puertas de las aulass de la Universidad de La Habana me entregó el libro Galería de Rebeldes, supe de las persecusiones y condenas que había sufrido. Al llegar a México dejaba atrás la época de la impetuosa lucha política en la militancia de los grupos de izquierda, donde se reunían los opositores de las dictaduras de Gerardo Machado y Fulgencio Batista. Después me enteré de que el retrato a lápiz publicado en el libro le había sido tomado durante su último encarcelamiento. El motivo de su condena fue un reportaje para la revista "Mundo Infantil" donde denunciaba la miseria, la enfermedad y el hambre que los ni. ños sufrían en el reparto de Las Yaguas, un barrio habanero. Los días de su reclusión vigorizaron su fortaleza de espíritu y le dieron el secreto de un ánimo indoblegable.

Al poco tiempo de estar en México, más por curiosidad y ansia de saber, que por una vocación clara, ingresó a la recién fundada Escuela Nacional de Antropología. Ahí nacería un vínculo con el Maestro Alfonso Caso que fue determinante en su carrera profesio- 
nal. Él lo llevó consigo a las exploraciones de Monte Albán, y, precisamente en el transcurso de la excavación, fue cuando se suscitó en Alberto Ruz un particular atractivo hacia la arqueología, de tal forma que decidió dedicarse a esta disciplina; como él mismo decía, fue ahí cuando descubrió cuál era "el prototipo del científico, el ejemplo a seguir" (Ruz, 1973: 366).

Con la impronta que Caso había dejado en su formación, y siguiendo el camino mostrado por el Maestro, al finalizar sus estudios buscó otras posibilidades de investigación y optó por dirigirse al área maya. Las exigencias de trabajos arqueológicos ahí y una particular inclinación a las tierras tropicales, lo llevaron a estudiar Campeche en la época prehispánica.

A partir de los inicios de su vida profesional (1943), todas sus reflexiones, conocimientos e investigaciones, los dejó por escrito. Nunca se guardó sus conclusiones; los resultados de cada uno de sus estudios, por mínimos que fueran, siempre salieron publicados.

De esa época, apenas egresado de la Escuela de Antropología, es un breve artículo llamado "Sentido humano de la arqueología" (1944). Los pensamientos contenidos en él tuvieron definitivo significado en su vida académica, porque fueron las ideas guías de toda ella.

Este ensayo es muestra de un afán incontenible de conocer el pasado; inquietud que consideraba inherente al hombre, y pensaba que "una manera artificial de prolongar los límites de nuestra vida es vivir retrospectivamente todos los siglos ya vividos, es prolongarnos en la búsqueda de eternidad" (Ruz, 1944: 114). En el caso de los pueblos que no dejaron su historia relatada, la arqueología era el método más seguro, la vía por medio de la cual se podía recrear ese pasado. Sostenía que tal disciplina no se reducía sólo a investigar la historia, sino debía tener otro objetivo más, éste era la "reconstrucción y restitución" porque "al reconstruir unas ruinas, dándole sentido a los vestigios arquitectónicos, borrando en parte los estragos de la vetustez, el arqueólogo devuelve a la vida el cadáver de una ciudad" (Ruz, 1944: p. 115). Pensaba que con ello podía restituir a la memoria de sus constructores los méritos alcanzados, para así enaltecer a sus creadores, un pueblo cuya civilización había sido degradada.

Después de dos años de dedicarse al trabajo arqueológico en el área maya, surgió la obra La costa de Campeche en los tiempos prehispánicos, que fue un hito en su vida profesional; con ella se graduó como arqueólogo obteniendo el primer título que se daba en México en tal especialidad. Pero sobre todo, aquella investigación dió una motivación especial a su carrera; fue durante su desarrollo cuando se gestó en Alberto Ruz algo que estaba latente desde que escogió a los 
mayas como objetivo de estudio: un amor a esa tierra y a sus hom. bres que le producía una aspiración continua de saber sobre su pa. sado y su presente. Este impulso fue creciendo con los años y se tradujo en una entrega completa a su conocimiento.

También es necesario expresar que en este libro ya se perfila cla. ramente aquello que va a caracterizar su labor científica. Todas sus afirmaciones se sostienen sólidamente en datos confiables; siempre se nutrió de información que le proporcionaban la etnografía, la lin. güística, la historia, la epigrafía y la historia del arte, de ahí que manejara los conceptos fundamentales de estas ciencias y, a veces, las cultivara en forma independiente. La meta en esta investigación y en las siguientes era ir más allá de la descripción de los datos objetivos, haciendo notar como insostenibles conceptos muy manejados en su época; su desacuerdo con ellos está expresado en su artículo "Arqueología maya. Trayectoria y meta", escrito en 1946, donde enfrenta el esquema acuñado por Morley con los conocimientos que había logrado conjuntar. El modelo de desarrollo histórico de los mayas dividido en dos grandes épocas llamadas Nuevo Imperio y Viejo Imperio Mayas resultaba carente de fundamento, por lo que además de hacer esto expreso, trazó un nuevo cuadro apoyado en datos arqueológicos, epigráficos e históricos. He querido insistir en esta gran aportación, porque si bien muchos la ignoraron en aquel tiempo, representó un importantísimo paso en los estudios mayas, proporcionándole nuevas perspectivas a la arqueología.

A partir de aquella época, y hasta 1958, fue director de excavaciones arqueológicas en Uxmal, Kabah y Palenque, siendo durante casi diez años jefe de la zona del sureste de la Dirección de Monumentos Prehispánicos del INAH.

El Maestro Ruz en cada artículo, en cada informe de excavación, hacía progresar los conocimientos sobre los mayas, ya sea aportando nuevos datos, dilucidando un hecho cultural, explicando un momento histórico o revisando los antiguos criterios para establecer unos novedosos mejor fundamentados. Casi diez años de trabajar en las rui. nas de los mayas, en convivencia estrecha con sus actuales descendientes, además de acrecentar su fervor a ese pueblo, le permitió llegar a una profunda comprensión de su ser histórico actual.

De todos estos trabajos las exploraciones en Palenque formaron un capítulo aparte, porque representaron el punto culminante de su carrera profesional. Emprendidas por un grupo de arqueólogos bajo su dirección, entre sus diversos objetivos destacaba la búsqueda de restos de una ocupación más antigua que la testificada por los edificios visibles. Así, durante la cuarta temporada de campo, descubrió la cá- 
mara funeraria y el sepulcro más suntuosos de la América indígena. La pirámide que sostenía el Templo de las Inscripciones, no era sólo el basamento de un templo como todas las estructuras de este tipo en Mesoamérica, sino el monumento que eternizaba la memoria de un hombre. Este maravilloso descubrimiento que tanta fama le dio, no sólo sirvió para sacar a la luz obras de arte creadas por los mayas, sino que también fue un medio para precisar varios aspectos de su civilización. Primero el Maestro Ruz publicó conceinzudos reportes de todos sus trabajos, después se lanzó a la tarea de estudiar a fondo todo lo que el Templo de las Inscripciones manifestaba, buscando los significados del conjunto y de cada uno de los elementos en particular, y ofreció una explicación de todo lo que estaba implícito en esta gran obra, desde el aspecto religioso hasta el artístico, pasando por el histórico, el económico y el socio-político en su libro publicado varios años después, El Templo de las Inscripciones: Palenque (1973).

Antes de este magnífico descubrimiento, pero ya embebido de la arquitectura y escultura palencanas escribió el ensayo "Universalidad, singularidad y pluralidad del Arte Maya" (1950), espléndida conceptuación del quehacer artístico de este pueblo.

A partir de este hecho, tanto instituciones nacionales como gobiernos extranjeros le confirieron premios y honores. Esto no le ensoberbeció sino que sólo aumentó su aspiración de difundir el conocimiento sobre la civilización maya, por lo que gustoso aceptaba continuamente dar conferencias sobre sus hallazgos o impartir cursos, así como escribir artículos de divulgación o para revistas especializadas nacionales y extranjeras. Dictó cátedras en la Academia de Ciencias de Cuba, en la Universidad de La Habana y en la Universidad de París, por citar las más relevantes. Igualmente se dirigía a públicos especializados en eruditas exposiciones científicas, que a grupos de aficionados a las cosas antiguas, a quienes les descubría el maravilloso mundo de los mayas. De uno de aquellos cursillos surgiría la primera suma general de sus conocimientos, el libro La civilización de los antiguos mayas (1957), primero editado en Cuba y luego en México, que fue tra. ducido a varios idiomas.

Creo que en este sentido su trabajo fue meritorio, porque ademá: de difundir la cultura maya a nivel nacional, ha sido el primero y el único arqueólogo mexicano en proyectar su labor en el extranjero.

A pesar de su experiencia y de sus conocimientos, no cesó de apren. der lo que otros podían enseñarle; por tanto, hizo estudios de posgrado en París y después de concluir los trabajos en Palenque, llevó cunsos de doctorado. Desde ese año, 1960, se desvinculó del Instituto Nacional de Antropología y entró en la Universidad Nacional Autó. 
noma de México, otro momento importante de su vida, puesto que crearía el Seminario de Cultura Maya, y tomaría relevancia su labor docente impartiendo la cátedra de Civilización Maya en la Facultad de Filosofía y Letras.

Su trabajo para obtener el grado de doctor en Ciencias Antropológicas y que le mereció el reconocimiento Suma Cum Laude, Costumbres funerarias de los antiguos mayas, constituye otra destacada contribución. Con el afán de indagar parte de las raíces más remotas, explicativas de la concepción mexicana de la muerte, se dedicó al estudio de las costumbres y prácticas funerarias de los mayas comparándolas con las de otras civilizaciones americanas y con los patrones seguidos universalmente. En su obra, en la que confluyen, nuevamen. te, informaciones de las ciencias que él conoció y aplicaba en sus investigaciones también plantea las implicaciones económicas, sociopolíticas e ideológicas de las costumbres en torno a la muerte.

Como maestro atendió a muchas generaciones, a nivel tanto de licenciatura como de posgrado. Durante unos seis años fui su alumna; era excelente expositor, sus clases de Civilización Maya estaban llenas de vitalidad; en forma amena y con un agudo sentido del humor, narraba sus experiencais en las excavaciones. Explicaba su forma de trabajo, sus hallazgos y su cercana convivencia con los indígenas mayas. Supo suscitar en los alumnos el interés por un mundo peculiar, todavía poco conocido pero con muchas perspectivas para futuras investigaciones. Como además de la arqueología había cultivado otras disciplinas fundamentales para el entendimiento cabal del mundo maya, en sus clases mostraba a los alumnos, aparte de los restos materiales de su cultura, cada uno de los diversos aspectos de la vida de ese pueblo.

Él contribuyó para que varios estudiantes que cursaban la carrera de historia decidieran su vocación de mayistas, y siempre se mostró dispuesto a brindarles asesoría y apoyo. En su seminario, con paciencia y sabiduría ponía orden en las ideas de los participantes y planeaba con cada uno la investigación a seguir. En las sesiones semanales enseñaba a escoger y a evaluar los datos precisos, necesarios para el estudio, a ordenarlos y a darles un sentido. Sujetaba a sus alumnos a un constante ritmo de trabajo que formaba en ellos la disciplina que él mismo seguía rígidamente. Asesoró muchas tesis; sin escatimar esfuerzos leía los escritos una y otra vez; más tarde entre el discípulo y el maestro había un fecundo diálogo que beneficiaba la investigación. Variass de estas tesis no sólo sirvieron para obtener grados aca. démicos, sino que constituyeron sólidas aportaciones al estudio de los mayas y fueron publicadas. Precisamente con un fin didáctico, 
en los últimos tiempos se dedicó a reunir todos sus conocimientos en una obra terminada hace unos cuantos meses que saldrá a la luz con el título El pueblo maya: ayer y hoy.

La aspiración de crear un cuerpo de especialistas dedicados únicamente a los mayas, cristalizó en 1970 con la fundación del Centro de Estudios Mayas dentro del seno de la UNAM. Puestas sus esperanzas en los investigadores, la creación de esta institución era para él dar continuidad a su obra, prolongar la búsqueda por desentrañar los secretos de la civilización maya.

El encuentro de Alberto Ruz con los mayas, fructificó en una ex. tensa y valiosa obra en la que él se cumple como ser humano y sus logros trascienden en un conocimiento más cabal de ese pueblo y de su cultura. 